$\xi=1$ 娄

\title{
Design and implementation of DPFC for multi-bus power system
}

\author{
B. Vijaya Krishna ${ }^{1 *}$, B. Venkata Prashanth ${ }^{2}$, P. Sujatha ${ }^{3}$ \\ ${ }^{1}$ Research Scholar, Department of EEE, JNTUA, Ananthapur \\ ${ }^{2}$ Professor \& Head, Department of EEE, QIS CET, Ongole \\ ${ }^{3}$ Professor, Department of EEE, JNTUA, Ananthapur \\ *Corresponding author E-mail: bvijayakrishna85@gmail.com
}

\begin{abstract}
In current days, the power quality issues in the interconnected power system are mainly happens due to the demand of electricity and utilization of large non-linear loads as well as inductive/capacitive loads. The power quality cries are voltage sag and swell in multi-bus power system (MBPS). In this article studies on a two bus, three bus and five bus power systems using DPFC. In order to eliminate the voltage sag and swell in the MBPS, a distributed power flow controller (DPFC) is designed. The structure of the DPFC consists of threephase shunt converter and three single series phase converters. Both these converters are arranged in back-back voltage source inverters (VSIs). These converters are controlled with help of the pulse width modulation (PWM) scheme. The feedback controllers and reference signals are derived the PWM for DPFC to magnify the power quality problems in MBPS. The performance of the model is investigated at different loads by making of MATLAB/Simulink model. The simulation results are presented.
\end{abstract}

Keywords: DPFC; Powerquality, Custompower Device; Feedback Controllers and MATLAB/Simulink.

\section{Introduction}

In current scenario, most of the researchers are finding the solution of power quality troubles in the power system and also its plays a major role in industrial, commercial and household applications. The major power quality troubles are considered here, voltage sag and voltage swell in the power system because of the faults and short circuits [1]. As per the customer view, the power problems are happen that will lead to the deviation in the voltage, current and frequency. In order to solve these power quality problems, flexible ac-transmission system (FACTS) is introduced and reported in [2-5]. The IEEE is defined by FACTS as power electronics based system and further static equipment that offer control of single or multi transmission system specifications to in crease the controllability as well as power transfer ability. Many FACTS devices are shunt active filter and series active filter, thyristor controlled reactor, thyristor switched capacitor/inductor, static variable compensator and unified power flow controller (UPFC) etc.,. Among these FACTS devices the UPFC is fast controlling device. Also, the main problem in the UPFC is D.C link capacitor. The size of this D.C link capacitor is large that will lead to more cost and need of large space. Suppose the D.C link capacitor is failure in UPFC which will lead to demolish the function of both the shunt and the series active filters. Owing to rectify these problems, a distributed power flow controller (DPFC) is designed [6-8]. DPFC is derived from the UPFC.

The performance of DPFC is same as function of UPFC to regulate all the power system parameters except elimination of D.C link capacitor between the shunt and series converters. The main benefits of the DPFC has small cost due to low voltage isolation and the small components rating of the series converter, good reliability owing to redundancy of series converter and real power exchange between the both converters of DPFC via transmission line at the third harmonic frequency. The feedback controllers and reference signals generation method for FACTS devices has been reported in [9-12]. The classical linear controller design for shunt and series converter of DPFC has been reported [13-14]. However, the results of this designed controller have produced medium performance in term of power quality in two bus power system. Design of power oscillation damping (POD) controller for DPFC applied in eight bus power system has been well presented [15-20]. Yet, the active power response of this controller has produced more start-up overshoot and more sustained oscillation in steady state region. Design fuzzy logic controller (FLC) and sliding mode controller for FACTS devices and DC-DC converters has been reported [21-28]. The FLC is one of the intelligent controllers and its design completely depends on the human decision making. The fuzzy rules base is derived with help of the system characteristics. The above pointed out problems in MBPS are rectify by designed DPFC with its controls.

Therefore, in this article presents the design and implementation of DPFC for MBPS. Here, two bus, three bus and five bus systems are considered as a MBPS.

DPFC is a new FACTS device and it is used to mitigate the voltage and the current deviation wave shapes and also, to enhance the power quality in short span of time. DPFC is derived from UPFC and it consists of one three phase shunt converter and many small autonomous series converters. It has ability to control the transmission line parameters such as line impedance, transmission angle and bus voltage magnitude. FLC is applied for both converters of DPFC. The performance of designed set-up is investigated at different load using FLC.

The organization of article as follows; Section 2 presents the principle and modeling of DPFC. The meticulous design of feedback controllers/reference signal generation for DPFC is explained in 
section 3. Section 4 addresses the simulation results and discussions of DPFC in MBPS with controllers. The conclusions are listed in section 5 .

\section{Principle and analysis of DPFC}

a) Principle

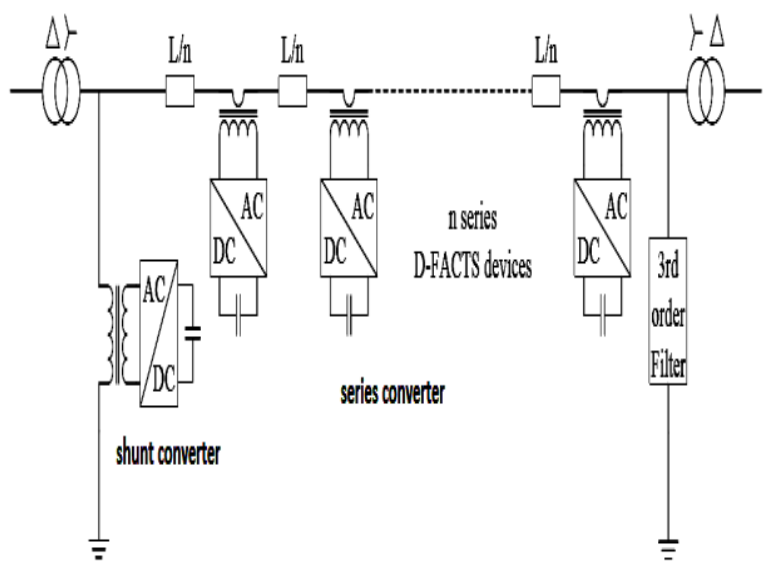

Fig. 1: Distributed Power Flow Controller.

The several individual converters are combined together to form the structure of DPFC is depicting in Fig. 1 [6]. The converters linked in series to transmission line are known as series converters. The function of it has injected the controllable voltage at the fundamental frequency that can lead the power flow control in the transmission line. The converter arranged between the transmission line and ground is called as shunt converter. The main function of shunt converter is to supply the real power needed by the series converter and also, to compensate the reactive power to the grid. While there is no D.C link capacitor linking the shunt and the series converter, the real power is replaced by harmonics and through the ac network. The principle is depended on term of real power, which is product of the average values of the voltage and the current. At the same time, these voltage and current contains fundamental and harmonics. As the integrals of entire cross product of terms with various frequencies are null, the real power can be written as equation (1) [6]

$$
P=\sum_{n=1}^{\infty} V_{n} I_{n} \cos \varphi_{n}
$$

Where,

$\Phi_{n}$ - phase angle between the voltage and the current of the $n^{\text {th }}$ harmonics.

From equation (1) explains that real powers at various frequencies are separated from each other and its voltage and current in one frequency has no influence on other frequency components. The $3^{\text {rd }}$ order harmonic is select here to exchange the real power in the DPFC, because it can be easily filtered with help of star (Y)-delta (D) transformers.

b) Steady State Analysis of DPFC

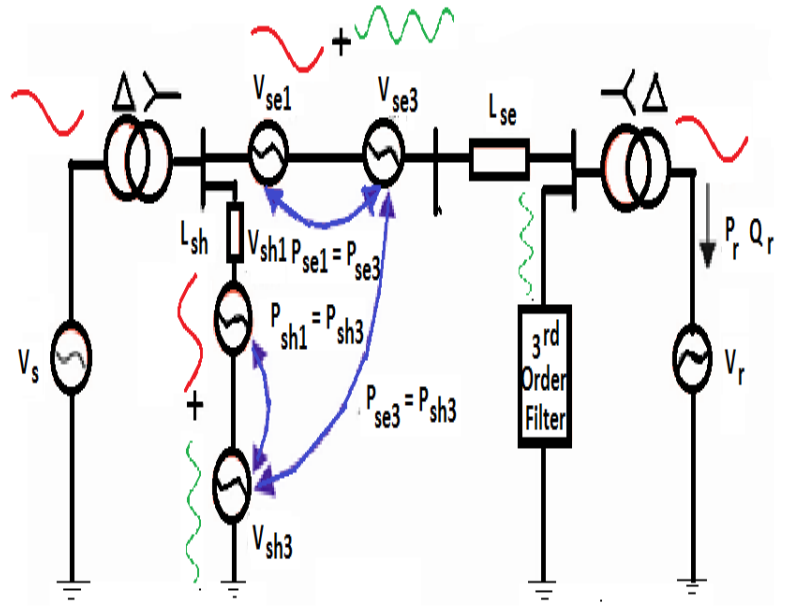

Fig. 2: Simplified Equivalent Circuit of DPFC in Two Bus Power System.

Every converter is replaced with regulate the voltage sources in series with impedance, and produces the voltage at two various frequencies. From the Fig.2, the DPFC is located in a two bus power system with the sending end and receiving end voltages $V_{s}$ and $\mathrm{V}_{\mathrm{r}}$, correspondingly.

The transmission line is represented with inductance ' $L$ ' and line current ' $I$ '. The injected voltage of series converters are $V_{\mathrm{sel}}$ and $\mathrm{V}_{\mathrm{se} 3}$ at fundamental and $3^{\text {rd }}$ order harmonic frequency components, correspondingly. The shunt converter is connected to the sending end bus via. inductor $\mathrm{L}_{\mathrm{sh}}$ and makes the voltages of $\mathrm{V}_{\mathrm{sh}}$ and $V_{\text {sh3 }}$ and also, the injected current of the shunt converter is represented by $\mathrm{I}_{\text {sh. }}$ The $\mathrm{P}_{\mathrm{r}}$ and $\mathrm{Q}_{\mathrm{r}}$ are receiving end real and reactive power flow and it can be engraved as equation (2).

$$
P_{r}+j Q_{r}=V_{r} * I_{1}^{*}=V_{r}\left(\frac{V_{s}-V_{r}-V_{s e l}}{j X_{1}}\right)^{*}
$$

Where,

$\mathrm{X}_{1}=\omega_{1} \mathrm{~L}-$ indicates the line impedance at the fundamental frequency.

The power flow without DPFC compensation $\mathrm{P}_{\text {ro }}$ and $\mathrm{Q}_{\text {ro }}$ can be written as

$$
P_{\mathrm{ro}}+\mathrm{jQ} \mathrm{Q}_{\mathrm{ro}}=\mathrm{V}_{\mathrm{r}}\left(\frac{\mathrm{V}_{\mathrm{s}}-\mathrm{V}_{\mathrm{r}}}{\mathrm{j} \mathrm{X}_{1}}\right)^{*}
$$

The power flow control range of the designed FACTS device can be written as equation (4)

$$
P_{r c}+j Q_{r c}=V_{r} \frac{V_{s e l}^{*}}{j X_{1}}
$$

Where,

$\mathrm{P}_{\mathrm{rc}}$ and $\mathrm{Q}_{\mathrm{rc}}$ - indicates the real and reactive power limit range of designed DPFC.

At fixed voltage at the receiving end and the transmission line impedance, the DPFC power flow control range is directly proportional to the peak voltage of the series converter, at the same time $\mathrm{V}_{\text {sel }} *$ shall be rotated over $360^{\circ}$, so regulating the real and the complex power transfer via. the transmission line. Using the equations (2) and (3), the control ability of the DPFC is expressed as (5)

$$
\left(P_{r}-P_{r o}\right)^{2}+j\left(Q_{r}-Q_{r o}\right)^{2}=\left(\frac{V\left|V_{s e l}\right|}{X_{1}}\right)^{2}
$$




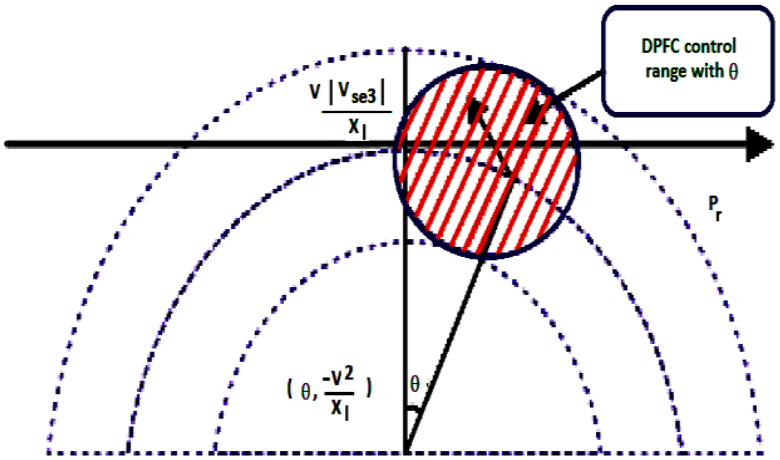

Fig. 3: DPFC Real and Reactive Power Control Range Using Transmission Angel.

The DPFC with its control range is represented the complex PQ plane in the form of circle as shown in Fig. 3. From this figure, it is clearly focused the locus of the power flow control without presence of the DPFC compensation $\mathrm{f}\left(\mathrm{P}_{\mathrm{ro}}, \mathrm{Q}_{\mathrm{ro}}\right)$ is a circle with radius of $\left|V^{2}\right| /\left|X_{1}\right|$ about its mid point (descried with coordinates $\mathrm{P}=0$ and $\mathrm{Q}=\left|\mathrm{V}^{2}\right| /\left|\mathrm{X}_{1}\right|$. Every point of this round circle offers $\mathrm{P}_{\mathrm{ro}}$ and $\mathrm{Q}_{\text {ro }}$ ranges of the un-compensated system at the related $\theta$. The possible boundary region for $\mathrm{P}_{\mathrm{r}}$ and $\mathrm{Q}_{\mathrm{r}}$ is arrived from a entire rotation of $\mathrm{V}_{\text {se1 }}$ with their peak amplitude as mentioned in the Fig. 3. The $\mathrm{V}_{\text {sel }}$ at fundamental frequency is expressed by

$\mathrm{V}_{\mathrm{sel}}=\frac{\left(\mathrm{S}_{\mathrm{r}}-\mathrm{S}_{\mathrm{ro}}\right) \mathrm{j} \mathrm{X}_{1}}{\mathrm{~V}_{\mathrm{r}}}$

Where,

$\mathrm{S}_{\mathrm{r}}$ and $\mathrm{S}_{\mathrm{ro}}-$ indicates the real power in compensated network and reactive power in non-compensated network.

In the direction of inject a $360^{\circ}$ rotatable voltage, a real and complex power by the fundamental frequency has to be supplied to the series converter, even though the complex power is nearby offered to the series converter and the necessity of real power is supplied by the shunt converter at the $3^{\text {rd }}$ harmonic frequency component via. the transmission line, and it is expressed as (7)

$$
\mathrm{P}_{\mathrm{sel}}=\frac{\mathrm{X}_{1}}{\left|\mathrm{~V}_{\mathrm{r}}\right|^{2}}\left|\mathrm{~S}_{\mathrm{r}}\right|\left|\mathrm{S}_{\mathrm{ro}}\right| \sin \left(\varphi_{\mathrm{ro}}-\varphi_{\mathrm{r}}\right)
$$

\section{Where,}

$\varphi_{\text {ro }}$ - indicates the power angle at the receiving end of the noncompensated system.

$\varphi_{\mathrm{r}}$ - indicates the power angle at the receiving end of the system with DPFC.

\section{Control methodology for DPFC}

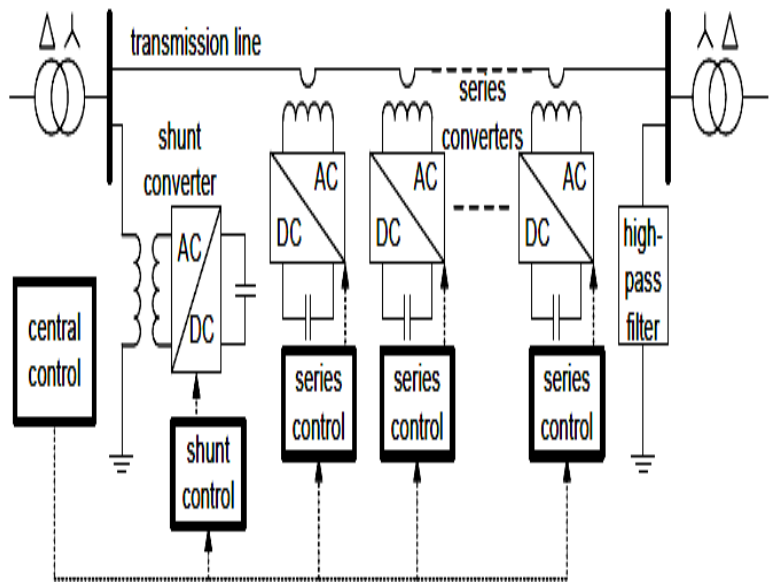

Fig. 4: Control block diagram of DPFC.
This section presents the controllers methodology for DPFC. Generally, the controllers for DPFC has three namely central control, shunt control and series control, rspectively. It is illustrated in Fig.4 [5-6].

a) Central Control

The central control unit (CCU) is produced reference signals and its generated reference signals are applied to both DPFC converters tenuously with help of the PLC communication technique. As per the system needs, the CCU makes the reference signal of $\mathrm{V}_{\text {selref }}$ for series control block and reference signal of $\mathrm{q}$ -

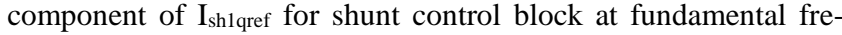
quency.

b) Series Control

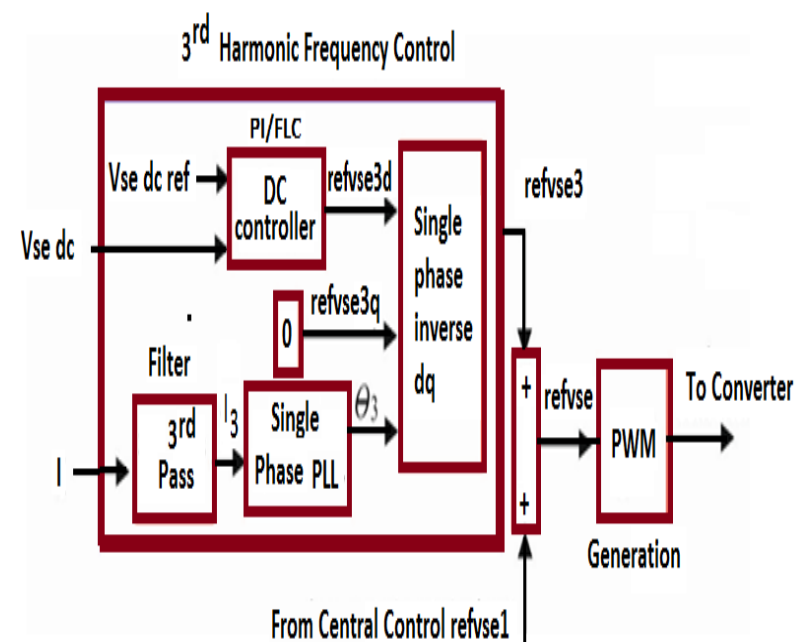

Fig. 5: Control Block Diagram of Series Converter.

Table 1: Fuzzy Rule Base Table of Shunt Converter/Series Converter Controllers

\begin{tabular}{|c|c|c|c|c|c|c|c|}
\hline ce & NB & NM & NS & $\mathrm{Z}$ & PS & PM & PB \\
\hline $\mathrm{NB}$ & $\mathrm{Z}$ & PB & NB & PB & NM & $\mathrm{NS}$ & Z \\
\hline NM & PS & PS & Z & NB & NS & $\mathrm{Z}$ & PS \\
\hline NS & PM & $\mathrm{Z}$ & PM & PB & $\mathrm{Z}$ & PS & PM \\
\hline Z & NB & NM & NS & $\mathrm{Z}$ & PS & Z & Z \\
\hline PS & NM & NS & PM & NS & NS & NM & NB \\
\hline PM & NS & $\mathrm{Z}$ & PS & PM & PM & NM & NB \\
\hline PB & Z & PS & NM & NB & PB & PB & PB \\
\hline
\end{tabular}

Output (o): $\mathrm{NB}=-1 ; \mathrm{NM}=-0.6546 ; \mathrm{NS}=-0.3344 ; \mathrm{Z}=0 ; \mathrm{PB}=1 ; \mathrm{PM} 0.6546 ;$ $\mathrm{PS}=0.3344$.

(A)

Membership Function Editor: TRIANGULAR

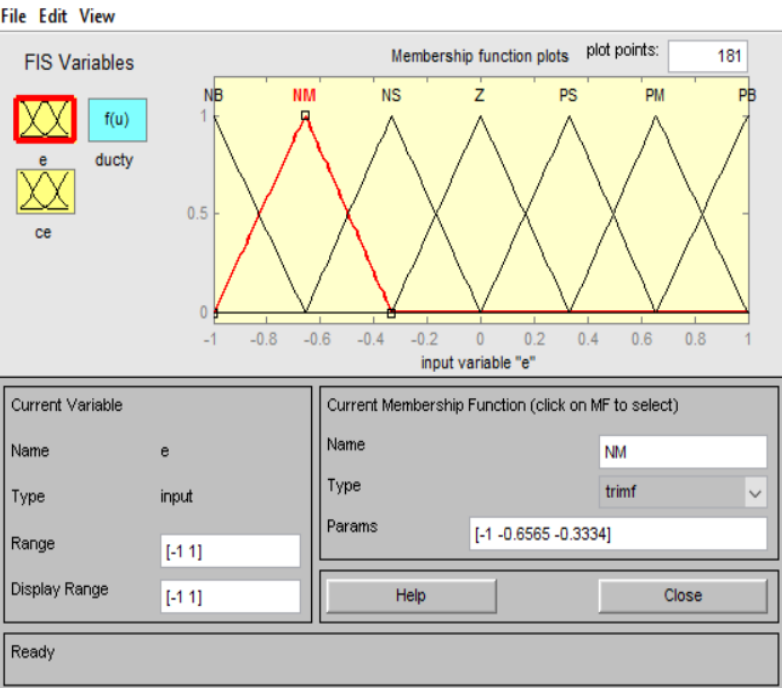


(B)

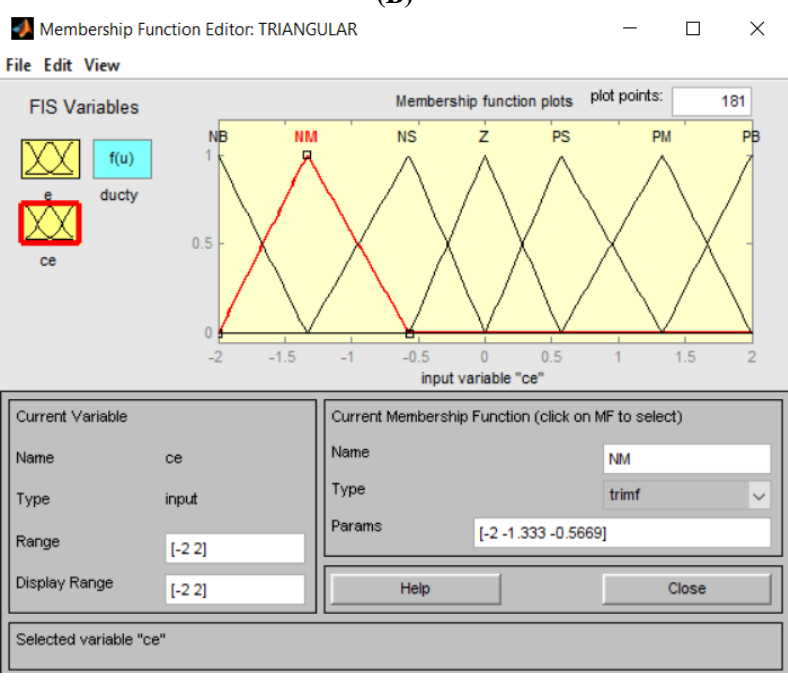

(C)

Membership Function Editor: TRIANGULAR

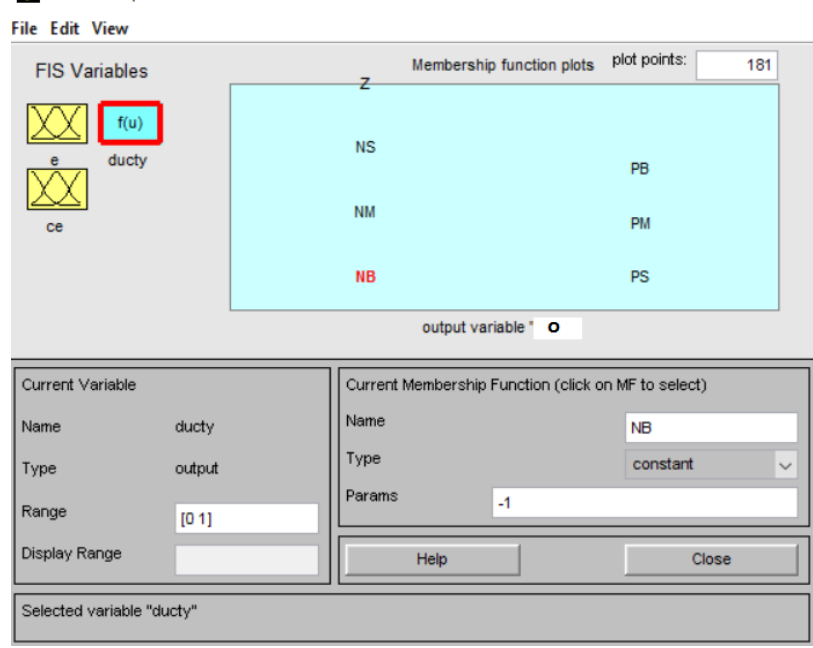

Fig. 6: Membership's Functions of FLC For DC Controller/Current Controller for Series and Shunt Converters of DPFC, (A) Error (E), (B) Change in Error (Ce), Aand (C) Output (O).

Surface Viewer: TRIANGULAR File Edit View Options

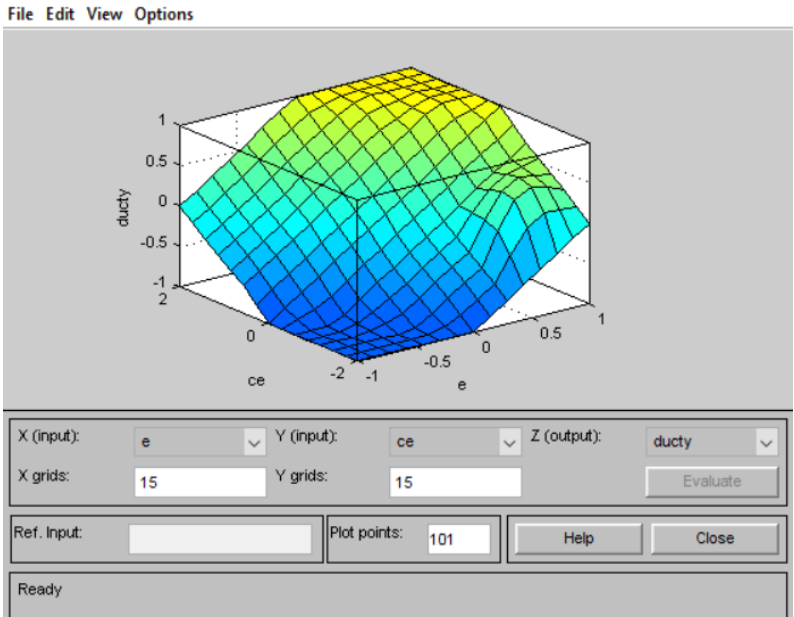

Fig. 7: Graphical Three-Dimensional (E, Ce and O) Surface View of Mmembership's Functions of FLC for DC Controller/Current Controller for Series and Shunt Converters of DPFC.

The function of the series converters has produce a magnified voltage magnitude with their phase angel under the fundamental frequency and also, $3^{\text {rd }}$ order harmonic frequency component is apply to absorb real power to keep its DC capacitor voltage magnitude at a fixed value. The main functional block diagram of
DPFC series converter control has central control, single phase PLL, DC controller, $3^{\text {rd }}$ pass filter, 1-phase inverse d-q and PWM generator (see Fig. 5). The vector control principle is utilized as control for series converter of DPFC. The principle is to transform the voltages and the current into a rotating reference frame like d$\mathrm{q}$ frame and convert ac quantities to DC with help of park transformation. In this case, single phase park transformation is used for single phase series converters. The $3^{\text {rd }}$ order harmonic current in the transmission line is chosen as the rotation reference frame for parks transformation for the reason that it can be measured simple by the series converter nearby with no additional cost. Since the transmission line contains two frequency components, a $3^{\text {rd }}$ order high pass filter is essential to separate the $3^{\text {rd }}$ harmonic current. Single-phase phase lock loop (PLL) track the line current magnitude with its angle and feed it to the single phase inverse parks transformation. The measured DC series voltage is compared with their reference signal and its error signal is processed through proportional integral (PI) controller and FLC to generate the control signal. The parameter of the PI is derived with help of the Ziegler Nicholas tuning method and its values are proportional gain $K_{p}=0.1$ and integral time $T_{i}=0.001 \mathrm{~s}$. Also, the FLC rules are arrived by series converter characteristics with no modeling of the converter. The main aim of designing the FLC is to control the parameters of DPFC and also it is placed inside/outside of the control loop of both series and shunt converter. Here, FLC has two inputs consists of voltage error (e) and change in voltage error (ce) and one output (o). Then, defuzzifiztion method (centroid method) is applied to complete the design procedure (see Fig. 6 and Fig. 7. The membership function of e, ce and o are illustrated in Fig.6 and its rules are listed in Table I.

For feasibility, the numerical ranges of the e, ce and o of the FLC can be identical and expressed in the Fig. 6 and its corresponding fuzzy sets are [NB, NM, NS, Z, PS, PM, PB] where, PS (positive small), PM (positive medium), PB (positive big), NB (negative big), NS (negative small), Z (zero), likewise. The triangular membership functions are opted as e and ce (see Fig.6). The qcomponent of the reference signal of the series converter at $3^{\text {rd }}$ order harmonic frequency component is maintained at zero in the operation. The DC quantities with phase angle are transformed back into ac with help of the inverse park's transformation. The reference signals of the both frequency components are combined to offers reference signal for series converters. It is applied to PWM block to generate the PWM gating pulses for series converters switches. Fig.7 indicates that the three-dimensional surface view of FLC in terms of e, ce and o.

c) Shunt Control

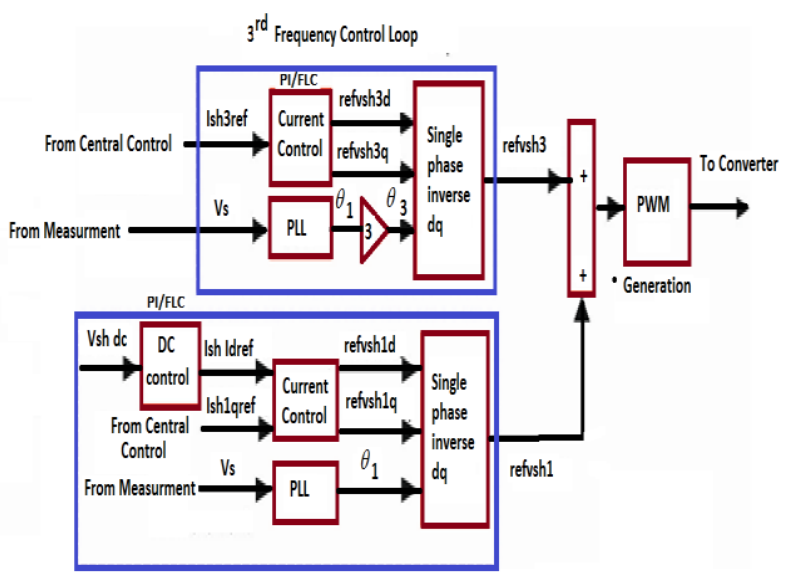

Fig. 8: Control Block Diagram of Shunt Converter.

The main function of this controller and its location were already discussed in the precious sections. The main control block of shunt converter of DPFC (see Fig. 8) has two namely fundamental frequency control loop (FFCL) and $3^{\text {rd }}$ order frequency control loop $\left(3^{\text {rd }} \mathrm{FCL}\right)$. Again, the FFCL consists of DC voltage control and current control. In FFCL, the bus voltage is chosen as rotation 
reference frame. The CCU and DC control is generated by the $\mathrm{q}$ component current and the $\mathrm{d}$ component reference signal. The current control is produces the desired control to the single-phase inverse parks transformation using PI controller and FLC. The $3^{\text {rd }} \mathrm{FCL}$ is generated the $3^{\text {rd }}$ order harmonic component of shunt converter of DPFC, which is synchronized with bus voltage at fundamental frequency. A PLL is applied to follow the bus voltage frequency and the output signal which are multiplied with constant " 3 " to produce the decoupled double synchronous rotation reference frame for the $3^{\text {rd }}$ harmonic current. The similar current control (PI control and FLC) is applied for $3^{\text {rd }}$ harmonic frequency components. Both the frequency control loops are combined to offer the reference signal for shunt converter of DPFC to maintain the DC link voltage constant and constant $3^{\text {rd }}$ harmonic current injected into the grid. Series converter rules and membership functions were applied for shunt converter also.

\section{Simulation results and discussions}

Table 2: Specifications of DPFC

\begin{tabular}{lll}
\hline Parameters & Symbol & Value \\
\hline SHUNT CONVERTER & & \\
Three Phase Shunt Transformer Details & RMS Voltage & $5 \mathrm{kV}$ \\
Winding 1 (delta) & RMS Voltage & $1 \mathrm{kV}$ \\
Winding 2 (star) & $\mathrm{C}$ & $1200 \mu \mathrm{F}$ \\
D.C link capacitors & & $380 \mathrm{~V}$ \\
D.C link voltage & & \\
SERIES CONVERTER & RMS Voltage & $1 \mathrm{kV}$ \\
Single Phase Series Transformer Details & RMS Voltage & $100 \mathrm{kV}$ \\
Winding 1 (delta) & Rinding 2 (star) & $6 \mathrm{kHz}$ \\
\hline Switching frequency & $\mathrm{f}_{\mathrm{s}}$ & \\
\hline
\end{tabular}

A main aim of this section is to simulation study of DPFC with designed controllers are performed in MATLAB/Simulink software platform. The specification applied for the study is catalogued in Table II. The validation of DPFC with PI controller/FLC performance is made for different operating loads (loads specifications are presented in the MATLAB/Simulink diagrams of MBPS). The results are discussed in p.u values.

a) Two-Bus System

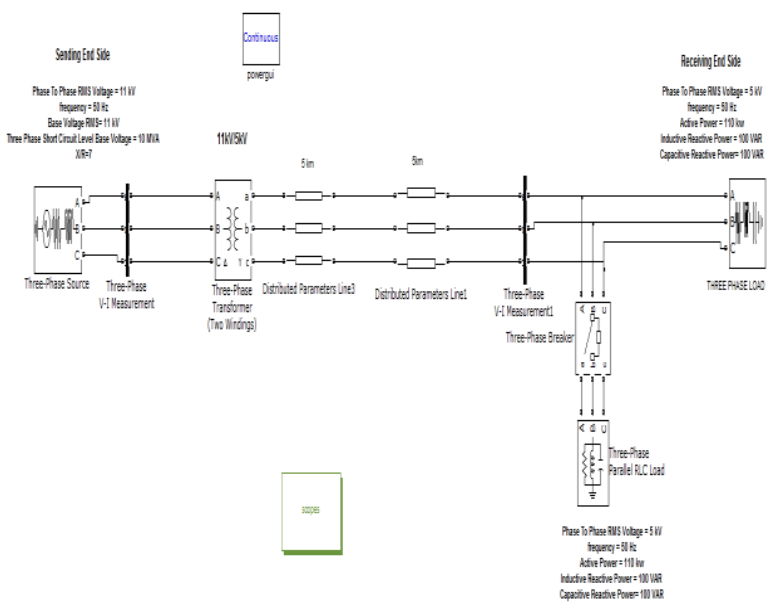

Fig. 9: MATLAB/Simulink Model of Two-Bus System without DPFC.

Fig. 9 shows the MATLAB/Simulink model of the two-bus system without DPFC. Fig. 10 show the simulation results of two-bus system without DPFC when load increased/decreased at bus-2 from the time of $0.08 \mathrm{~s}$ to $0.12 \mathrm{~s}$. It is clearly focused that the bus-2 voltage and current has swell and sag occurs without DPFC. Fig. 11 shows the MATLAB/Simulink model of two-bus system with DPFC. Figs. 12, 13 and 14 shows the simulation results of the two-bus system with DPFC at different loads change using PI controller and FLC. From these results, it is found that the designed DPFC with controllers has removed the voltage/current sag as well as swell. Also, the real power has improved and reactive has falls down with DPFC using controllers.

(A)

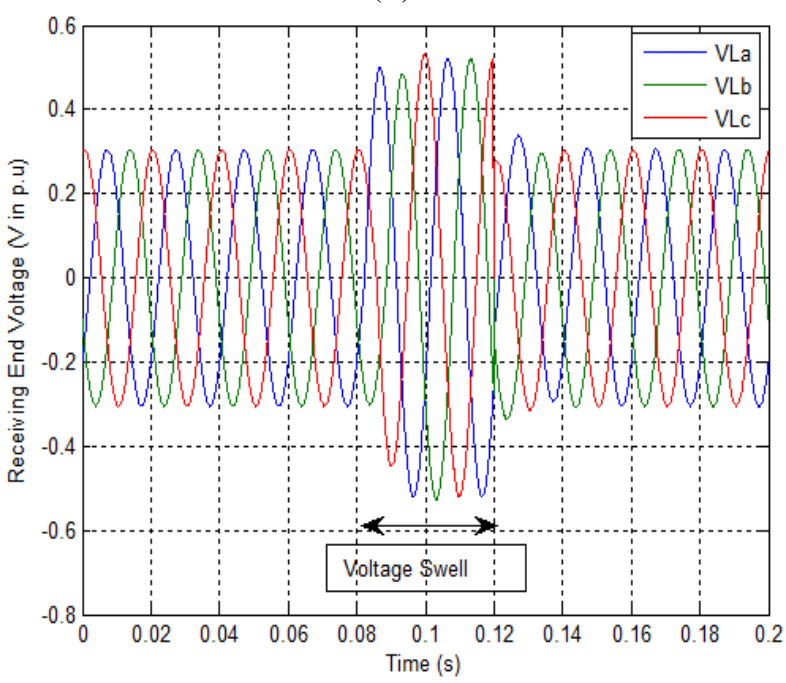

(B)

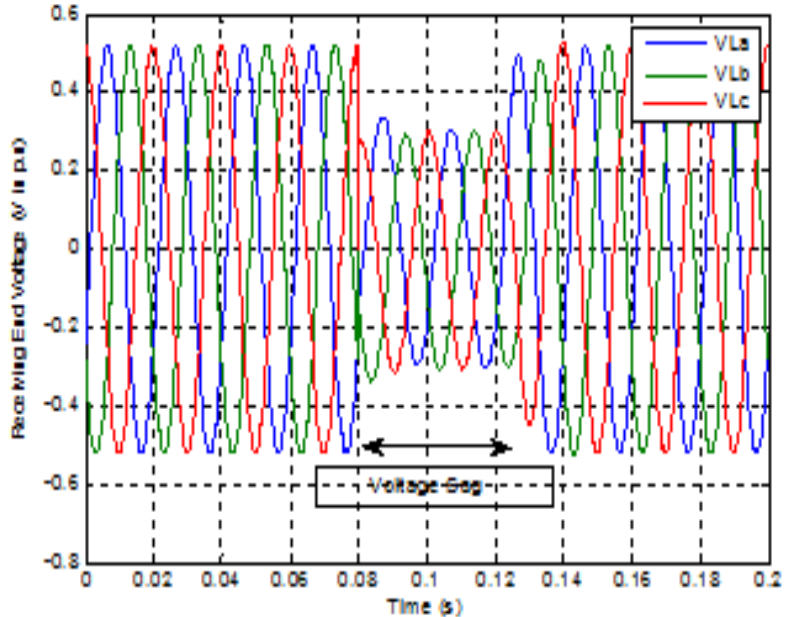

(C)

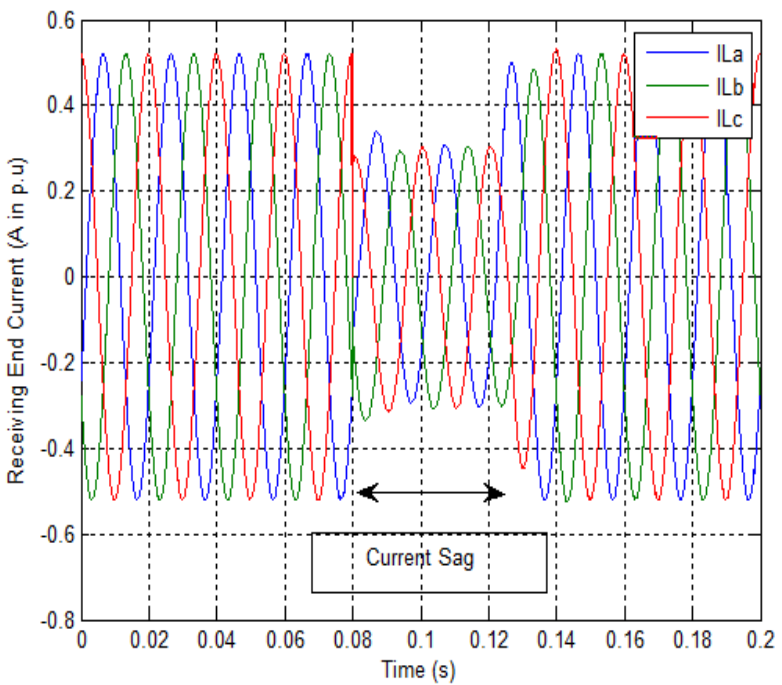

Fig. 10: Simulation Results of Two-Bus System without DPFC, (A) Bus-2 Voltage in Swell, (B) Bus-2 Voltage in Sag And (C) Bus-2 Current in Sag. 


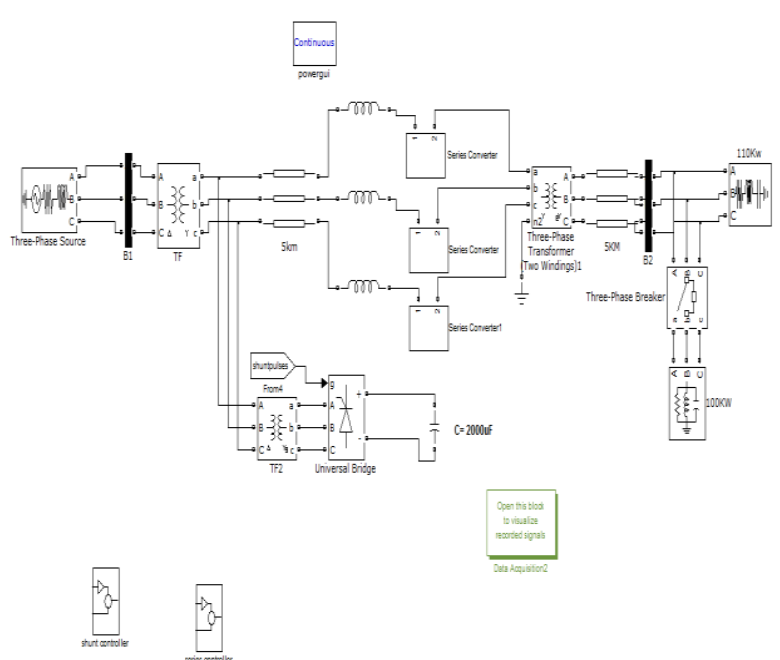

Fig. 11: MATLAB/Simulink Model of Two-Bus System with DPFC.

(A)

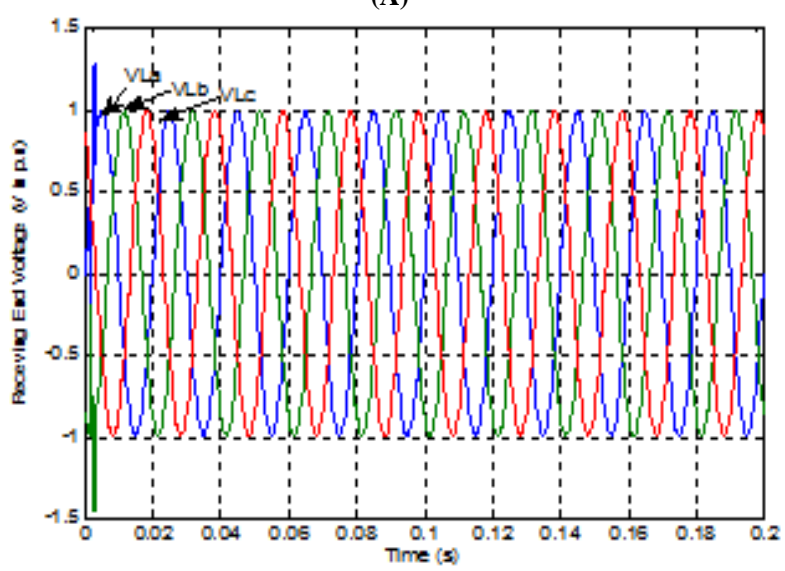

(B)

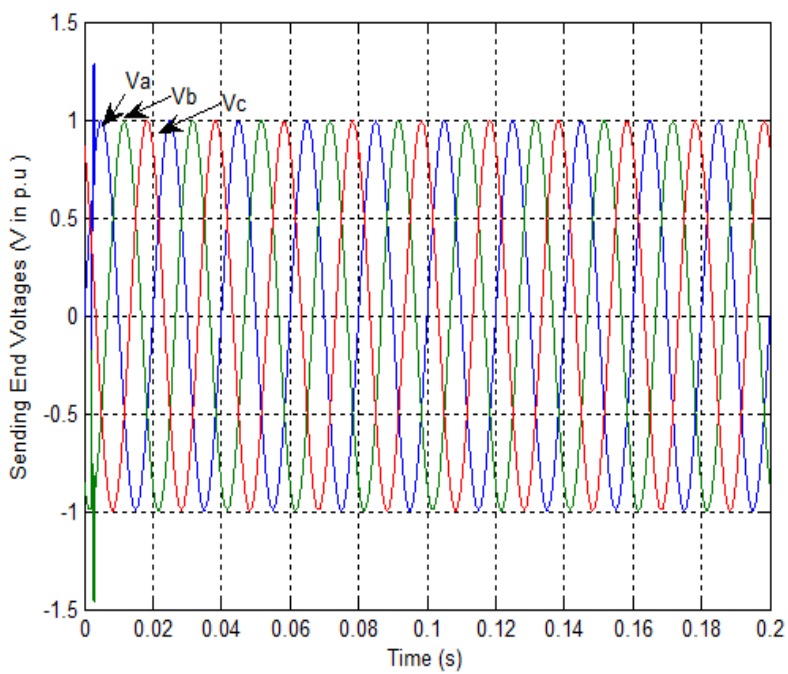

Fig. 12: Simulation Results of Two-Bus System with DPFC Using PI Controller, (A) Elimination of Bus-2 Voltage in Swell, (B) Elimination of Bus-2 Voltage in Sag and (C) Elimination of Bus-2 Current in Sag.

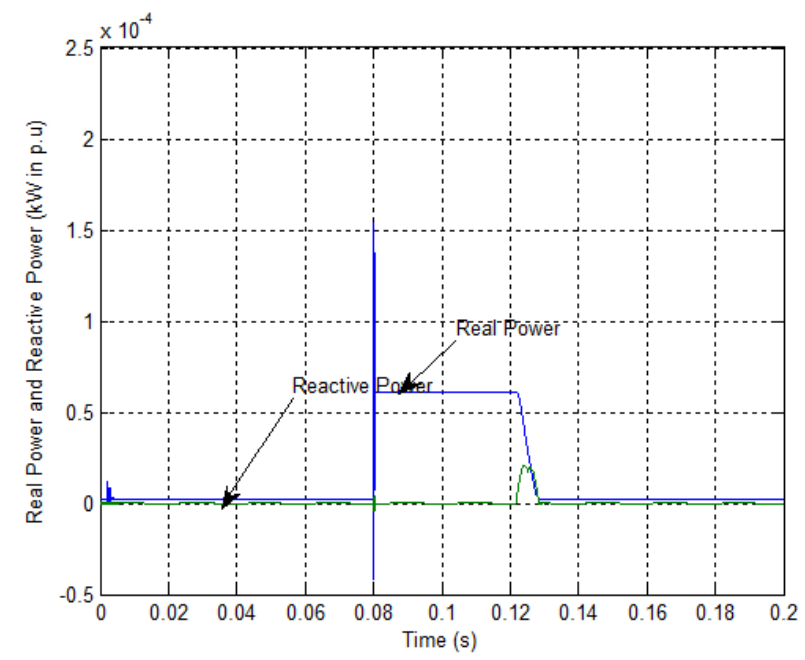

Fig. 13: Simulation Real and Reactive Powers Results of Two-Bus System with DPFC.

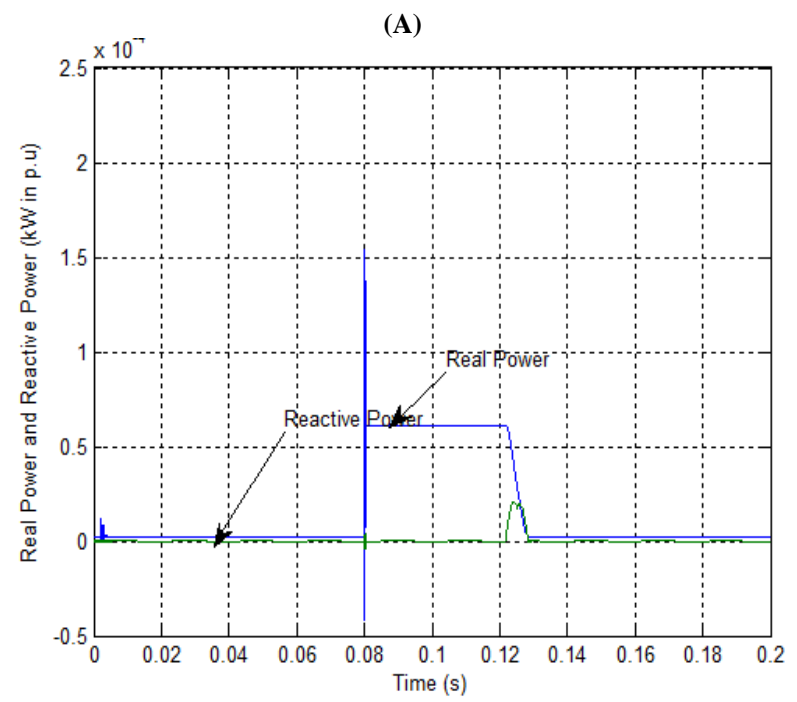

(B)

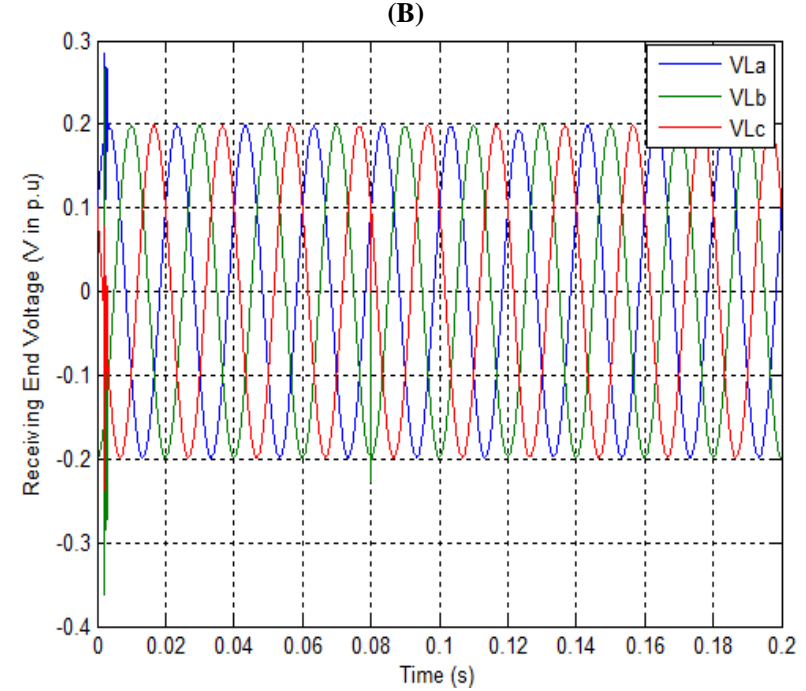

Fig. 14: Simulation Real/ Reactive Powers Bus-2 Voltage Results of DPFC with FLC.

b)Three-Bus System 


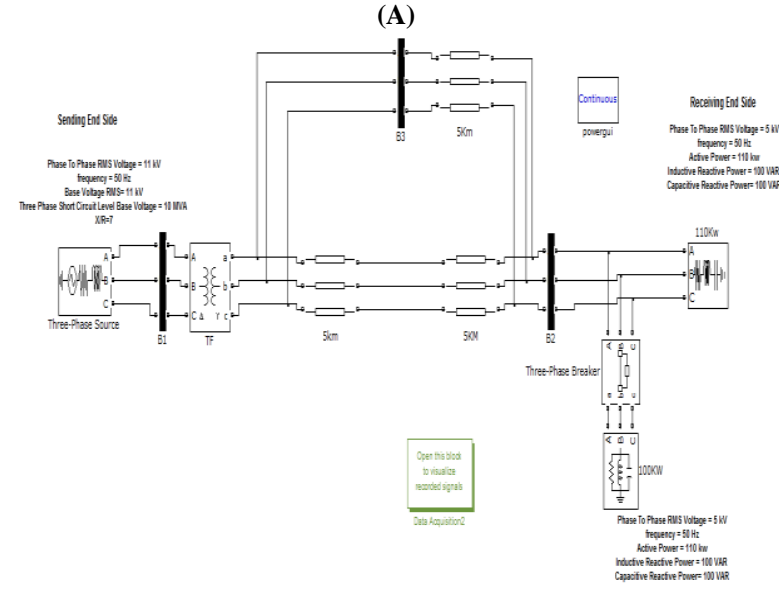

(B)

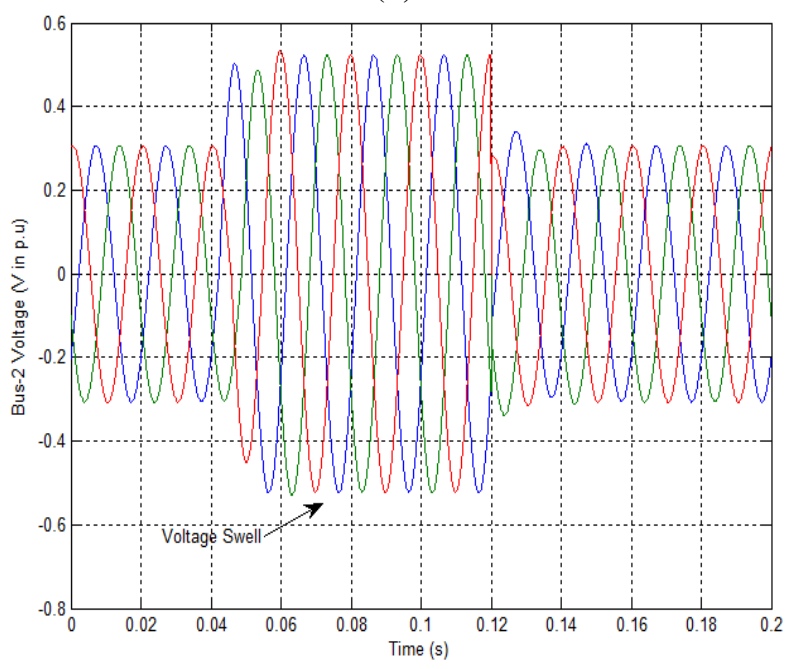

(C)

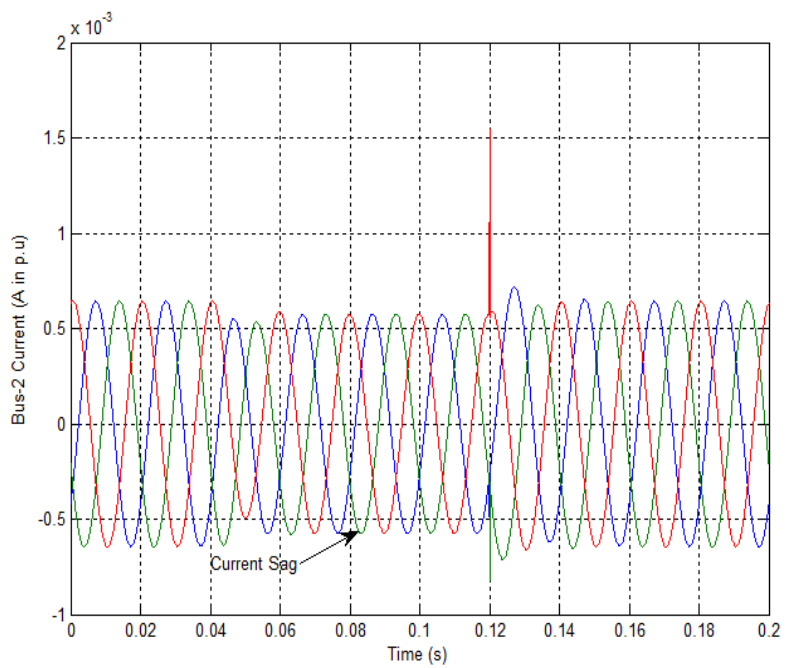

(D)

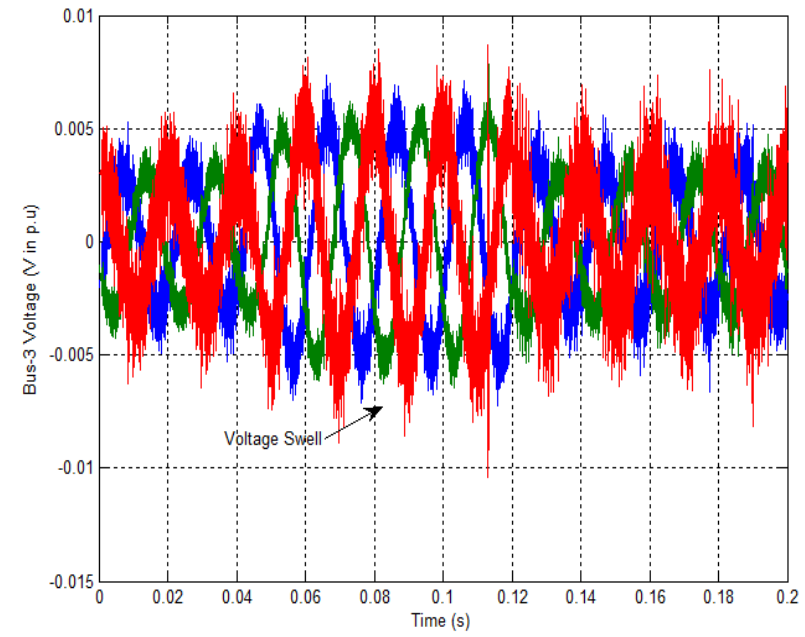

(E)

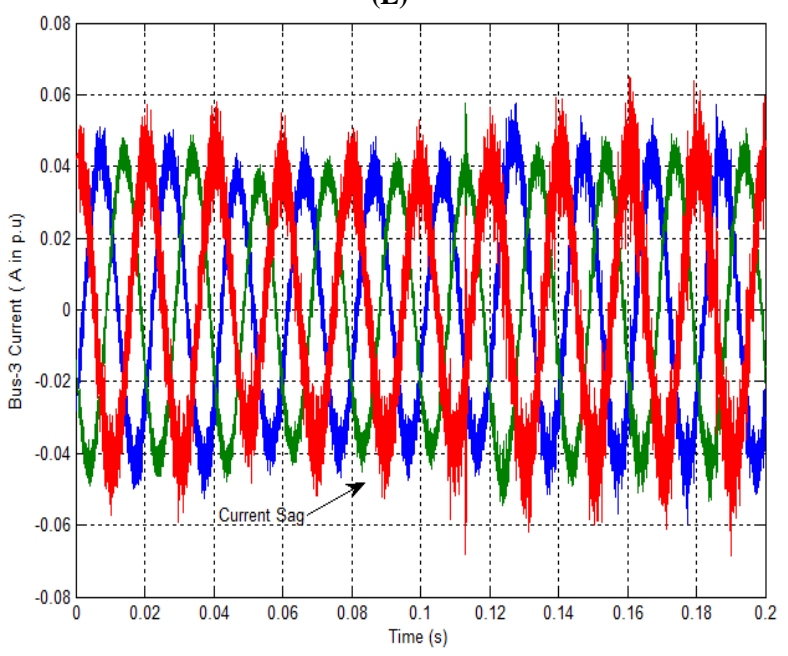

Fig. 15: Performance of Three-Bus System with No DPFC, (A) MATLAB/Simulink Model, (B) Bus-2 Voltage, (C) Bus-2 Current, (D) Bus-3 Voltage and (E) Bus-3 Current

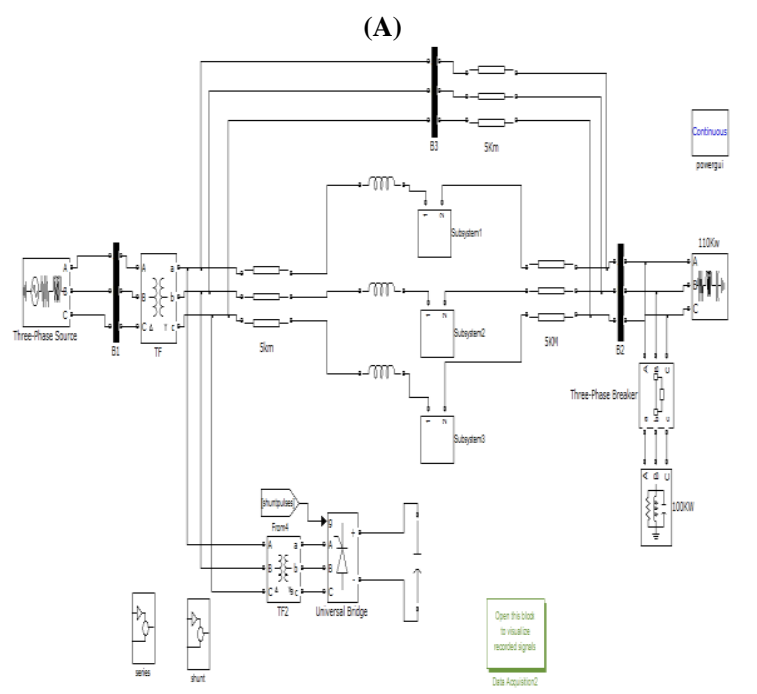


(B)

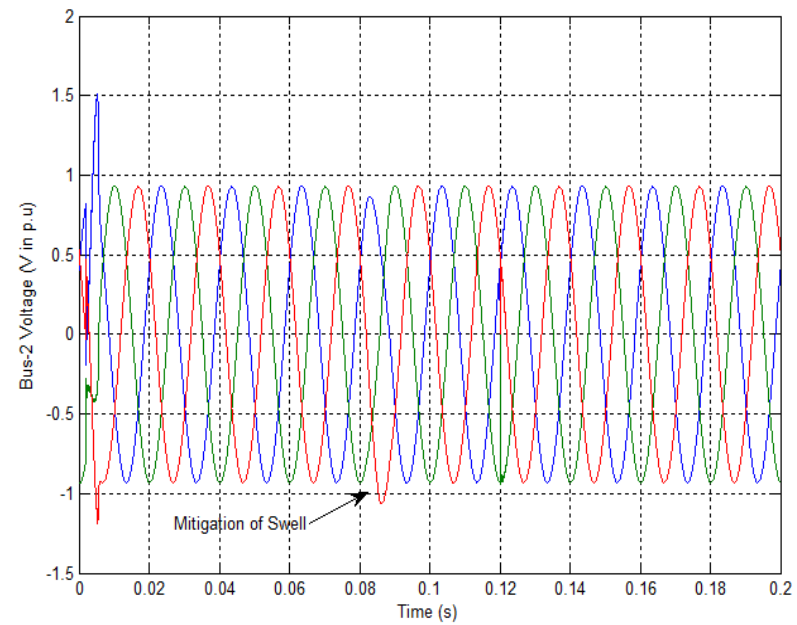

(C)

\section{Buss:2 Current $|A p, u|$}

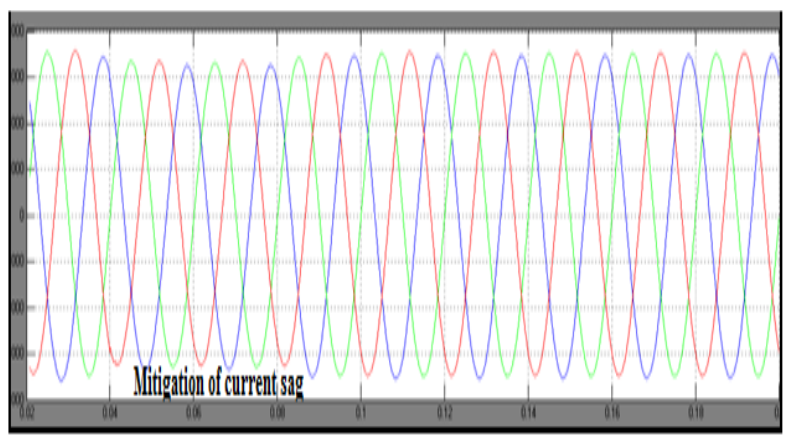

Timels)

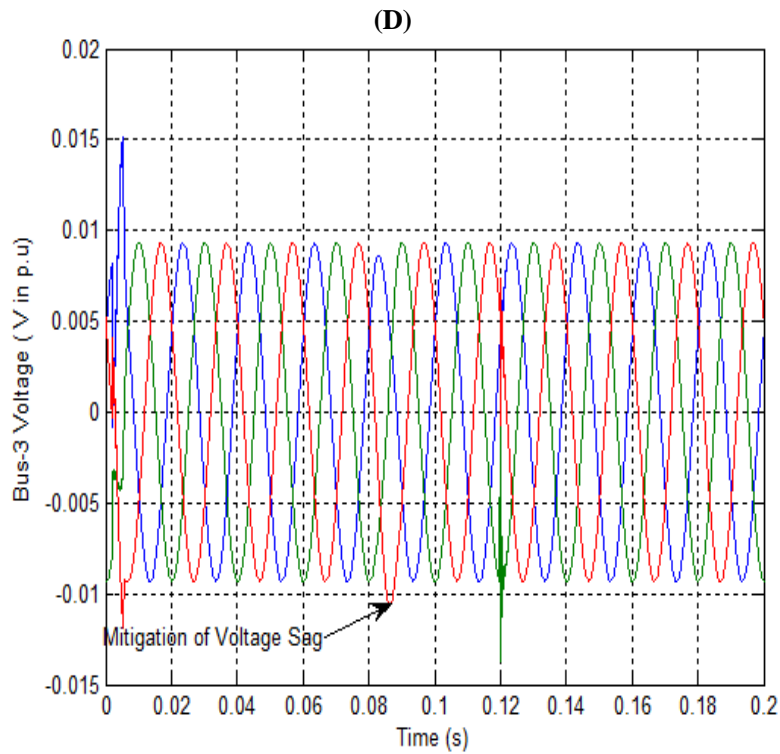

(E)

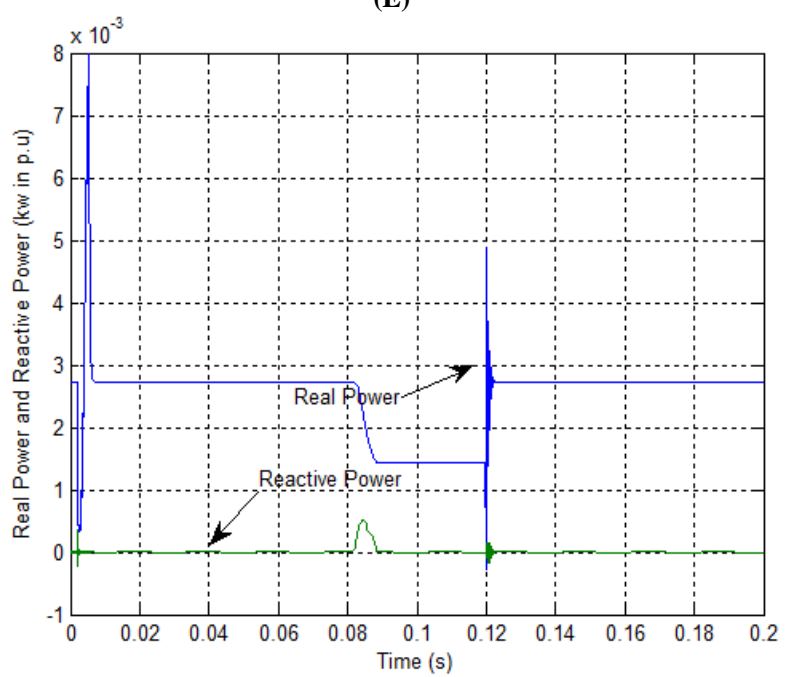

Fig. 16: Performance of Three-Bus System with DPFC Using PI Controller, (A) MATLAB/Simulink Model, (B) Bus-2 Voltage, (C) Bus-2 Current, (D) Bus-3 Voltage and (E) Real and Reactive Power at Bus-2

(A)

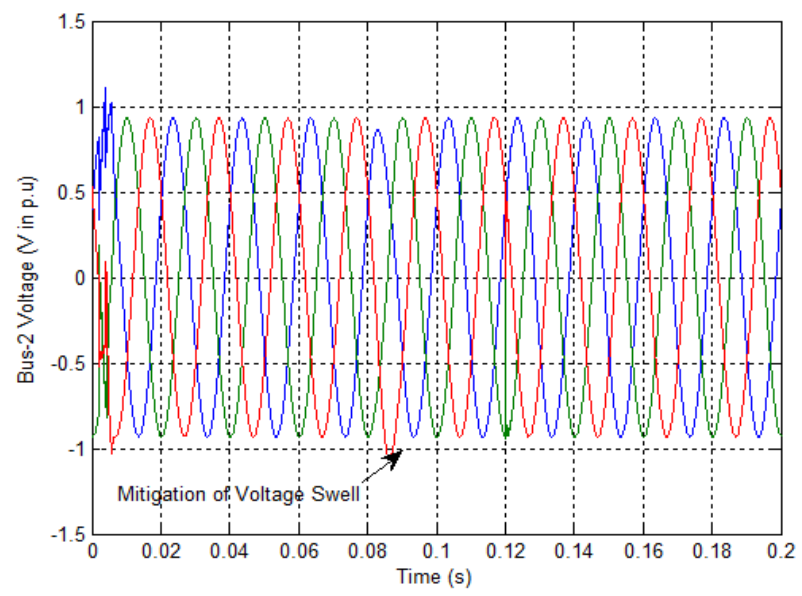

(B)

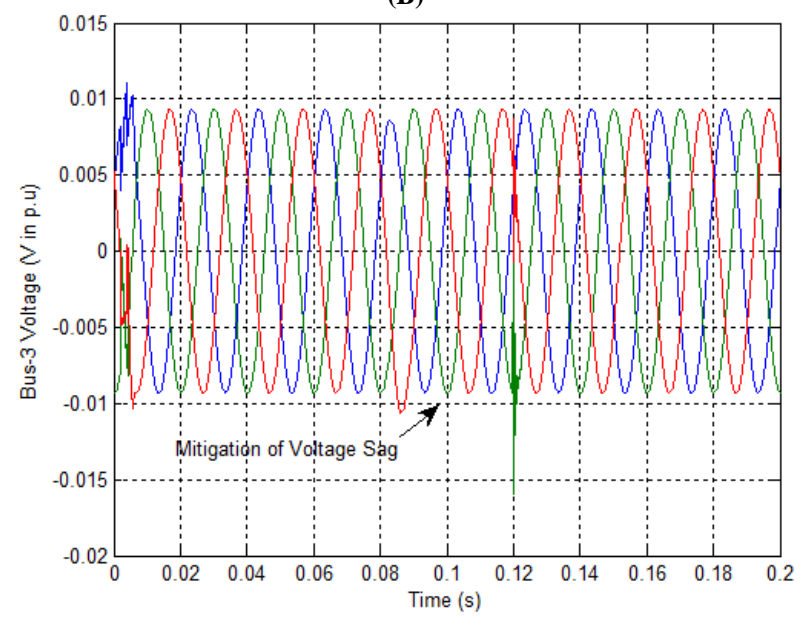


(C)

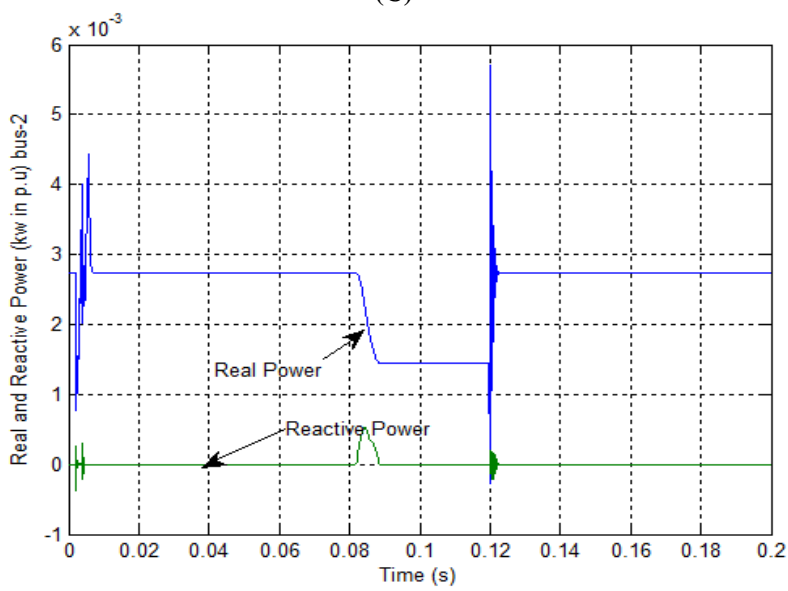

(D)

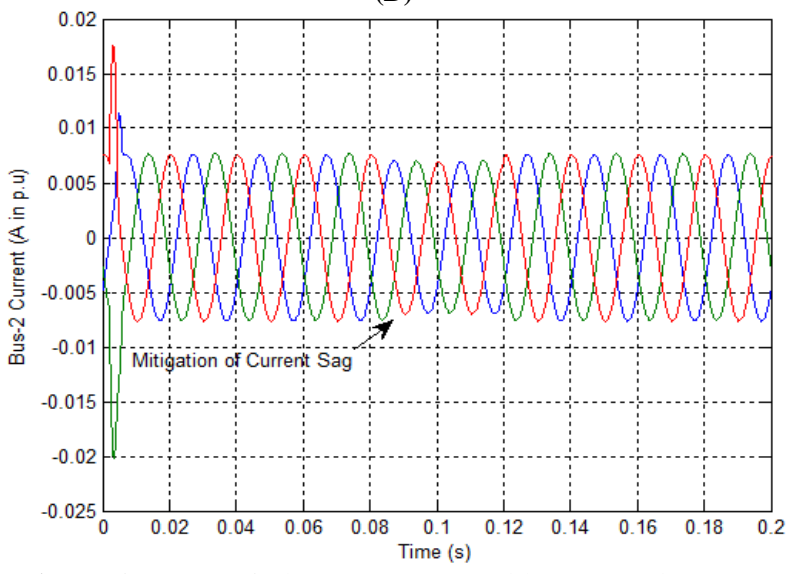

Fig. 17: Performance of Three-Bus System with DPFC Using FLC, (A) Bus-2 Voltage, (B) Bus-3 Voltage and (C) Real and Reactive Power at Bus-2 and (D) Bus-2 Current

Fig. 15 shows the performance of the three-bus system with no DPFC. From these results, it is clearly found that the MATLAB/Simulink model, bus- 2 voltage and current and bus-3 voltage and current of three bus system has produced sag and swell during the load variation at starts from $0.04 \mathrm{~s}$ to $0.12 \mathrm{~s}$ with no DPFC. Fig. 16 and Fig. 17 show the simulation results of threebus system with DPFC is connected between bus-2 and bus-3. It is clearly evident that designed model with controllers has mitigated the voltage and the current sag/swell and also produced enhanced real power and decreased reactive power.

c) Five-Bus System

Fig. 18 shows the performance of the five-bus system with no DPFC. From these results, it is clearly found that the MATLAB/Simulink model, bus-1 voltage and current and bus-4 voltage and current of five bus system has produced sag and swell during the load variation at starts from $0.08 \mathrm{~s}$ to $0.12 \mathrm{~s}$ without DPFC. Fig. 19 and Fig. 20 show the simulation results of five-bus system with DPFC is connected between bus-1 and bus-4. It is clearly identified that designed model with controllers has mitigated the voltage and the current sag/swell and also generated good real power and decreased reactive power.

Fig. 21 shows the D.C link capacitor voltage of shunt converter with FLC. It is clearly identified that the capacitor voltage of shunt converter has quick settling time and no peak overshoots. Finally, the designed DPFC for MBPS with both the PI controller and FLC were performed at different load conditions. Among these results, the FLC has excellent performance over the PI controller.
Table 3: Domain Specifications of Shunt Converter D.C Link Voltage of DPFC with FLC

\begin{tabular}{ll}
\hline Parameters & Value \\
\hline Settling time & $0.0001 \mathrm{~s}$ \\
Peak overshoots & nill \\
Steady state error & nill \\
\hline
\end{tabular}

(A)

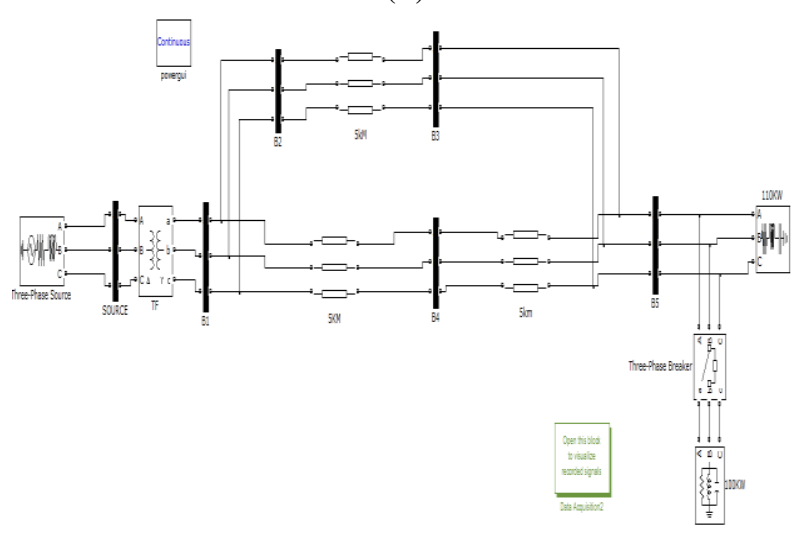

(B)

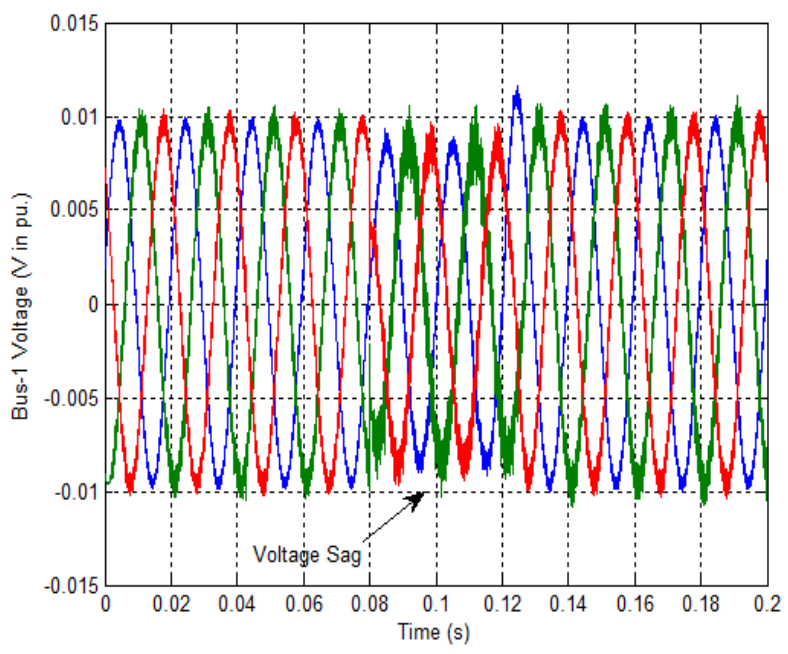

(C)

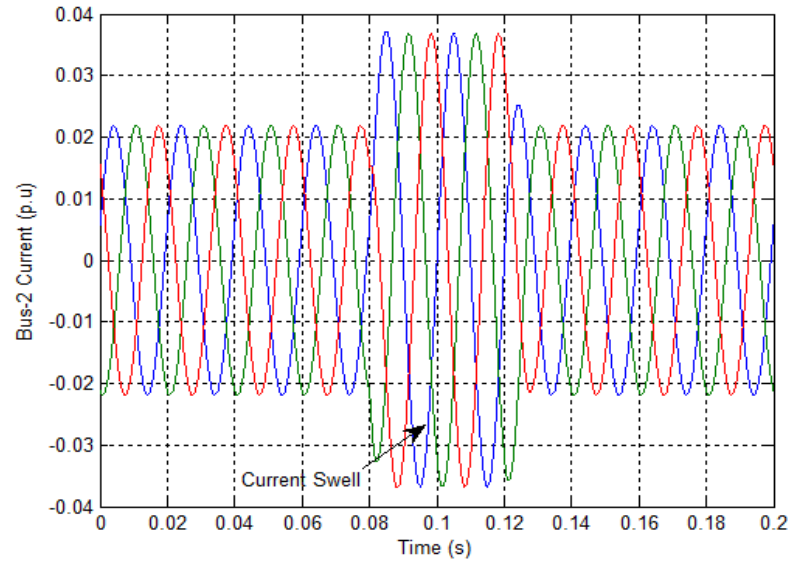


(D)

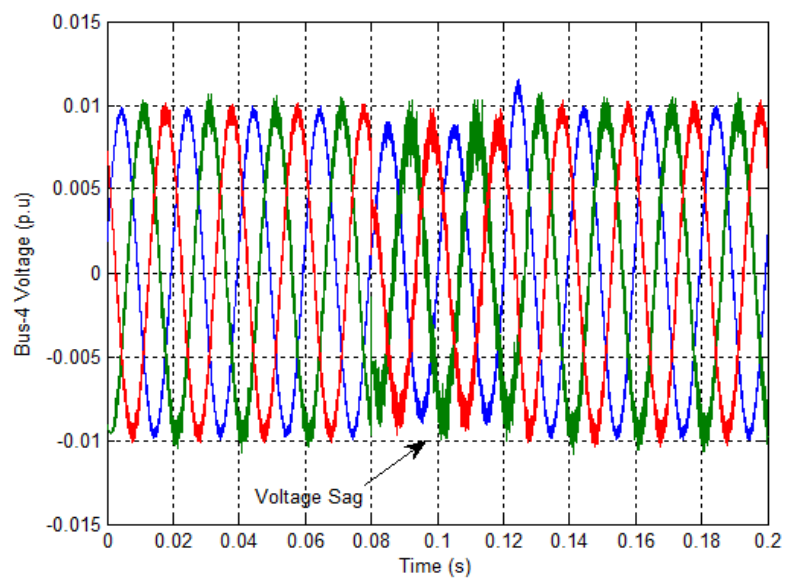

(E)

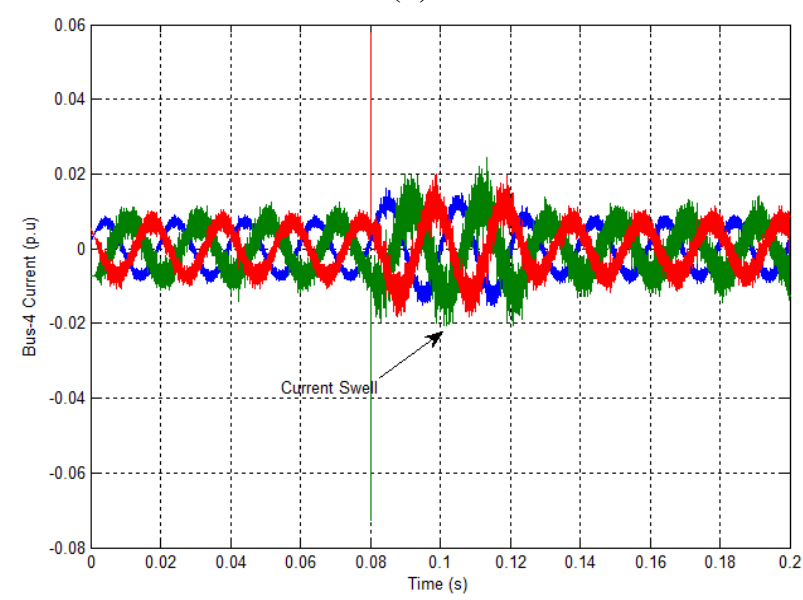

Fig. 18: Performance of Five-Bus System with No DPFC, (A) MATLAB/Simulink Model, (B) Bus-1 Voltage, (C) Bus-1 Current, (D) Bus-4 Voltage and (E) Bus-4 Current

(A)

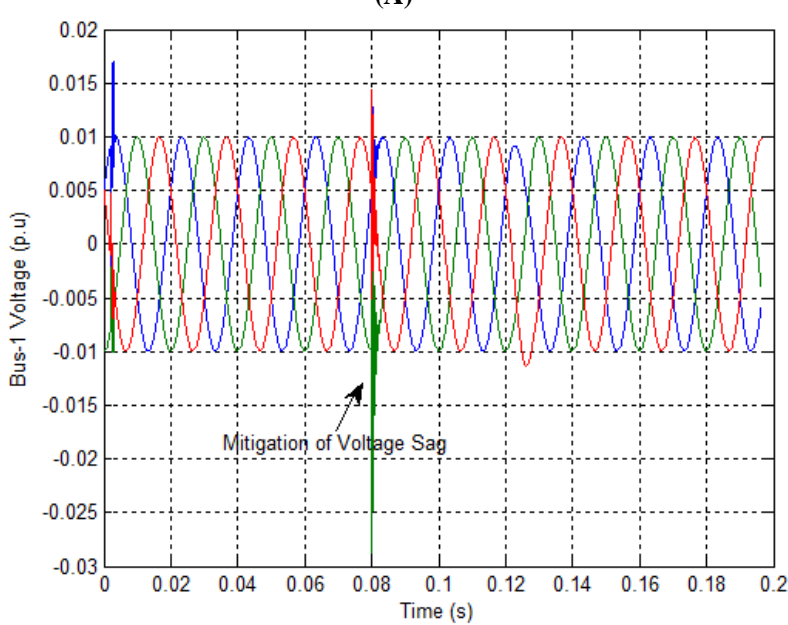

(B)

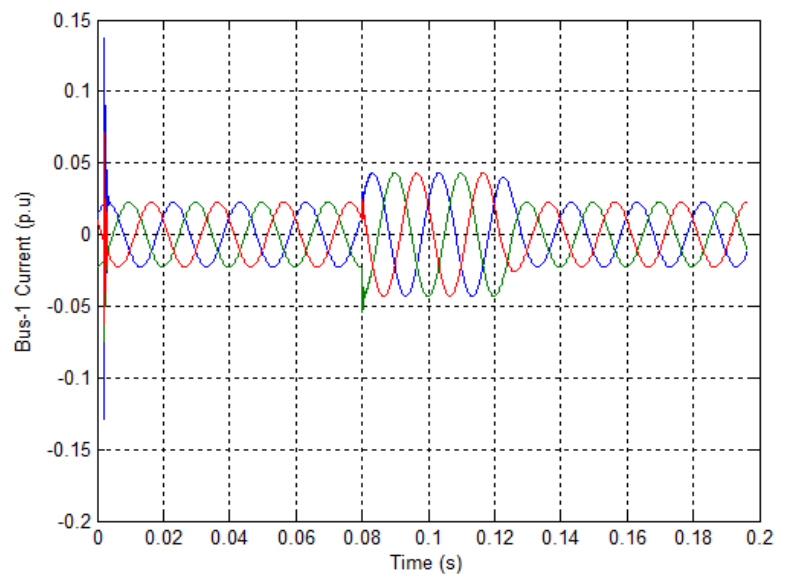

(C)

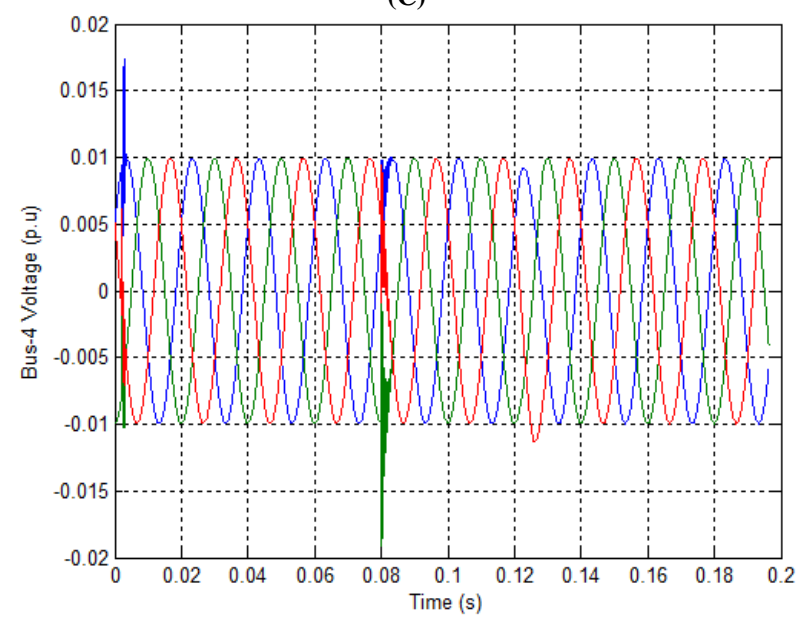

(D)

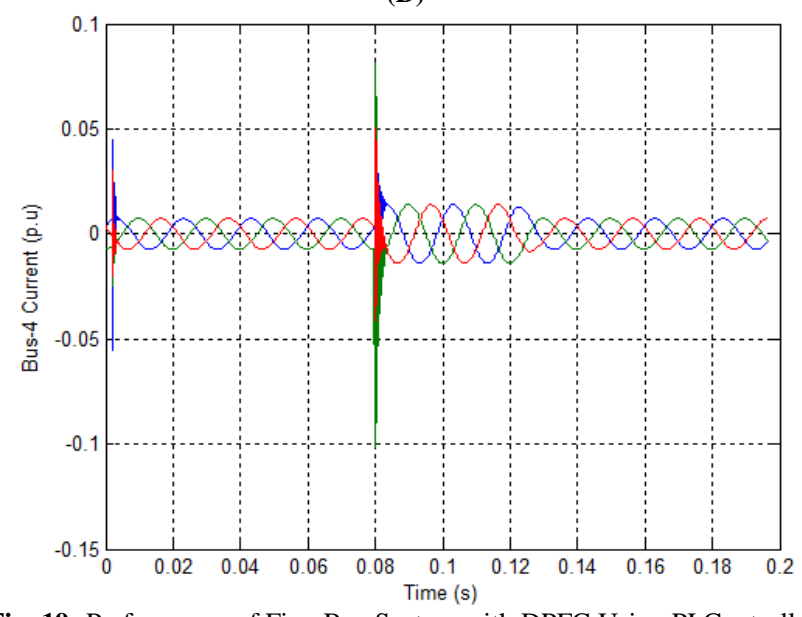

Fig. 19: Performance of Five-Bus System with DPFC Using PI Controller, (A) Bus-1 Voltage, (B) Bus-1 Current, (C) Bus-4 Voltage and (D) Bus-4 Current. 
(A)

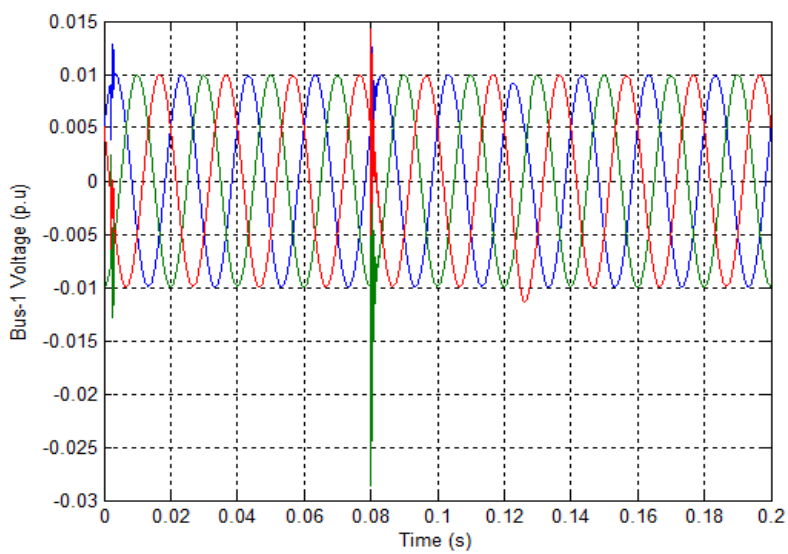

(B)

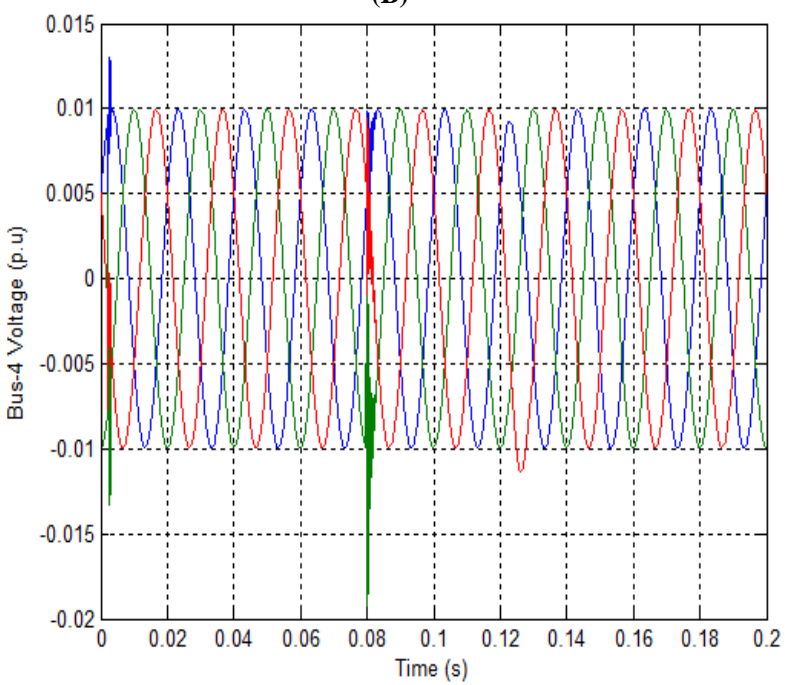

(C)

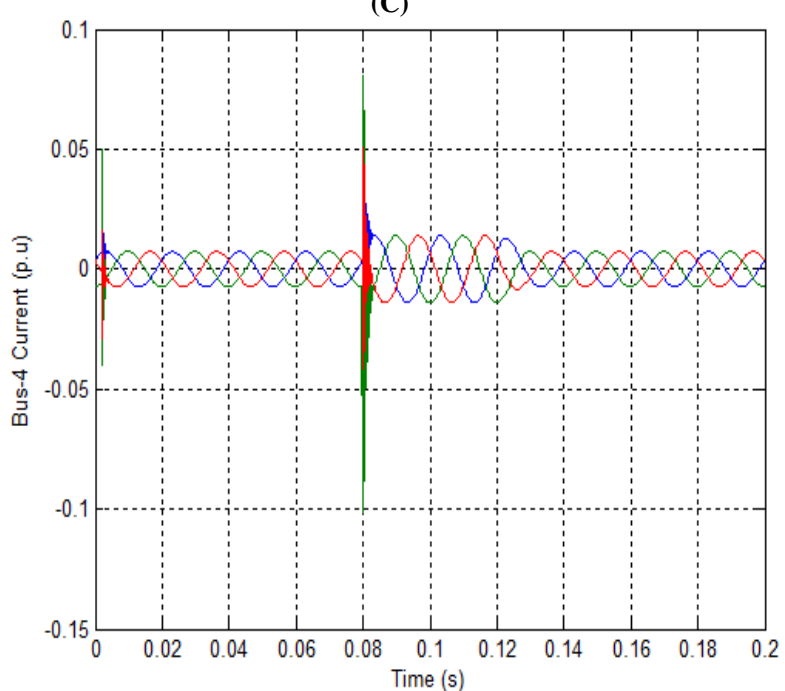

Fig. 20: Performance of Five-Bus System with DPFC Using FLC, (A) Bus-1 Voltage, (B) Bus-4 Voltage, (C) Bus-4 Current and (D) Real and Reactive Power at Bus-1.

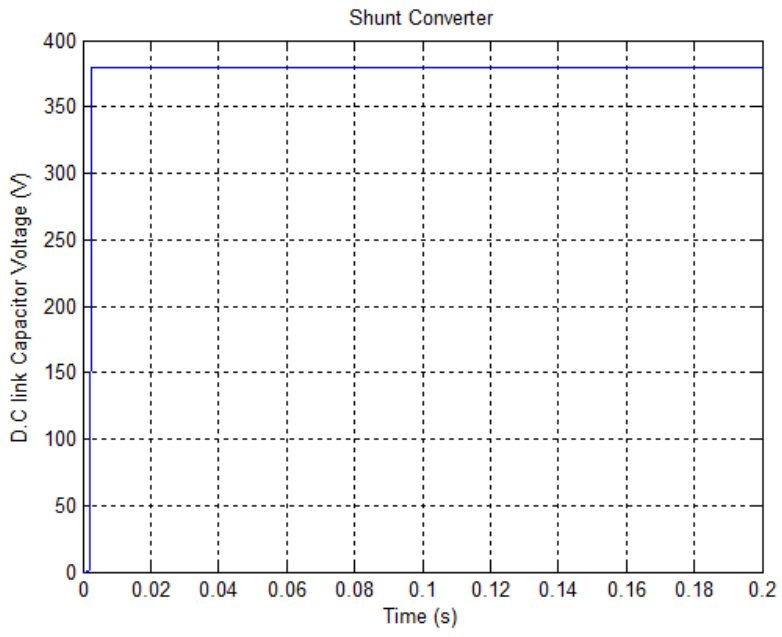

Fig. 21: D.C Link Capacitor Voltage of Shunt Converter Using FLC.

\section{Conclusions}

In this article, a design and implementation of DPFC for MBPS has been successfully simulated through computer simulation using MATLAB/Simulink. The many of the simulation results are presented to observe the proficient of the designed DPFC using FLC for the MBPS at various loads in comparison with PI controller. The designed model completely mitigated the voltage/current sag and the swell in different buses connection at different loads operating conditions. The quality of real and reactive of MBPS with DPFC has improved extraordinary. The D.C link capacitor voltage of the shunt converter using FLC has good time domain specifications.

\section{References}

[1] Y.-H. Song and A. Johns, Flexible ac Transmission Systems (FACTS) (IEE Power and Energy Series), vol. 30. London, U.K. Institution of Electrical Engineers, 1999.

[2] Samir Gautam, Pei Yunqing, Muhammad Kashif, Yubaraj Kafle, Liu Yibo, "DC Side voltage Control Consideration for Single Phase Shunt Active Power Filter for Harmonic and Reactive Power Compensation," Journal of Electrical Engineering, Vol. 15, Edition. 4, 2015, pp. 290-297.

[3] K. Ramash Kumar,'Implementation of Sliding Mode Controller plus Proportional Integral Controller for Negative Output Elementary Boost Converter," Alexandria Engineering Journal (Elsevier), 2016, Vol. 55, No. 2, pp. 1429-1445 https://doi.org/10.1016/j.aej.2016.03.027.

[4] Arunkumar, T.S. Sivakumaran, K. Ramash Kumar, "Improved Performance of Linear Quadratic Regulator plus Fuzzy Logic Controller for Positive Output Super Lift Luo-Converter," Journal of Electrical Engineering, Vol. 16, Edition:3, 2016, pp. 397-408.

[5] K. Ramash Kumar, S. Jeevananthan, "Hysteresis Modulation Based Sliding Mode Control for Positive Output Elementary Super Lift Luo Converter", World Academy of Science, Engineering and Technology, Volume. 2, No. 3, pp. 131-138, December 2009

[6] K. Mohanadasse, C. Sharmeela, T.D. Sudhakar, "Filters for Power Quality Improvement - A Survey," Australian Journal of Basic and Applied Sciences, Vol.9, No. 2, February 2015, pp. 8193.

[7] N. G. Hingorani and L. Gyugyi, Understanding FACTS : Concepts and Technology of Flexible AC Transmission Systems. New York: IEEE Press, 2000.

[8] K. Ramash Kumar, D.Kalyankumar, DR.V.Kirbakaran” An Hybrid Multi level Inverter Based DSTATCOM Control, Majlesi Journal of Electrical Engineering, Vol. 5. No. 2, pp. 17-22, June 2011

[9] Zhihui Yuan, Sjoerd W.H. de Haan, Braham Ferreira, "Utilizing Distributed Power Flow Controller (DPFC) for Power Oscillation Damping," IEEE conference, 978-1-4244-4241-6/09/\$25.00 (C)2009 IEEE.

[10] B.VijayaKrishna,B.VenkataPrashanth,K.S.R.Anjaneyulu"Desig ning of Multilevel DPFC to Improve Power Quality” IEEE conference 2016978-1-4673-9939-5/16@2016 IEEE. 
[11] Kuldeep Saini, Aakash Saxena, MR Farooqi, "Analysis of Distributed Power Flow Controller in Power System Network for Improving Power Flow Control," Indonesian Journal of Electrical Engineering and Computer Science, Vol. 2, No. 3, June 2016, pp. 510- 521. https://doi.org/10.11591/ijeecs.v2.i3.pp510-521.

[12] K. Ramash Kumar, Dr. S. Jeevananthan,” Design of Sliding Mode Control for Negative Output Elementary Super Lift Luo Converter Operated in Continuous Conduction Mode", (IEEE conference Proceeding of ICCCCT-2010), pp. 138-148, 978-1-42447768-5/10.

[13] K. Ramash Kumar, Dr.S. Jeevananthan," Design of a Hybrid Posicast Control for a DC-DC Boost Converter Operated in Continuous Conduction Mode" (IEEE-conference PROCEEDINGS OF ICETECT 2011), pp-240-248, 978-1-4244-7925-2/11.

[14] Zhihui Yuan, Sjoerd W.H. de Haan, Jan Braham Ferreira "DPFC design Procedure-a Case Study Using the KEPCO UPFC as an Example," KIEE International Transactions on Power Engineering, 2010, 3A, pp. 2696-2701. https://doi.org/10.1109/IPEC.2010.5542343.

[15] K. Ramash Kumar, S. Jeevananthan, S. Ramamurthy" Improved Performance of the Positive Output Elementary Split Inductor-Type Boost Converter using Sliding Mode Controller plus Fuzzy Logic Controller, WSEAS TRANSACTIONS on SYSTEMS and CONTROL, Volume 9, 2014, pp. 215-228.

[16] S. Senthamil Selvan, K. Ramash Kumar, R. Bensraj, "Modeling, Simulation and Design of Variable Structure Based Sliding Mode Controller for KY-Voltage Boosting Converter, WSEAS TRANSACTIONS on Circuit and System, Vol. 15, 2016, Art, pp. $143-154$

[17] N. Arunkumar, T.S. Sivakumaran, K. Ramash Kumar, S Saranya, "Reduced Order Linear Quadratic Regulator plus Proportional Double Integral Based Controller for a Positive Output Elementary Super Lift Luo-Converter," JOURNAL OF THEORETICAL AND APPLIED INFORMATION TECHNOLOGY, July 2014. Vol. 65 No.3, pp. 890-901.

[18] Deepak Divan and Harjeet Johal. "Distributed facts-A new concept for realizing grid power flow control," IEEE Trans. on Power Electronics. 2007; Vol. 22, No. 6, pp. 2253-2260. https://doi.org/10.1109/TPEL.2007.909252.

[19] K. Ramash Kumar, S. Jeevananthan, "A Sliding Mode Control for Positive Output Elementary Luo Converter," Journal of Electrical Engineering, Volume 10/4, December 2010, pp. 115-127.

[20] M Sateesh Kumar Reddy, N Narasimhulu, "A New Distributed Power Flow Controller to Improve the Power Quality by Mitigating Voltage Sag and Swell," International Journal of Engineering Research \& Technology (IJERT), ISSN: 2278-0181, 2013, Vol. 2 No. 9, pp. 1623-1627.

[21] A. S. Padma, Dr. R. Lakshmipathi, K. Ramash Kumar and C. P. Nandagopal,"A PI Controller for Enhancing the Transient Stability of Multi Pulse Inverter Based Static Synchronous Series Compensator (SSSC) With Superconducting Magnetic Energy Storage (SMES)", World Academy of Science, Engineering and Technology, Volume. 3, No. 3, pp. 136-142, summer 2010, eISSN 20103778 .

[22] Yuan Z, de Haan SWH, Ferreira B, "Control Scheme to Improve DPFC Performance during Series Converter Failures". IEEE Power and Energy Society General Meeting (PESGM), Minneapolis, USA. https://doi.org/10.1109/PES.2010.5590010.

[23] R. Belaidi, A. Haddouche, H. Guendouz,'Fuzzy Logic Controller Based Three-Phase Shunt Active Power Filter for Compensating Harmonics and Reactive Power under Unbalanced Mains Voltages," Energy Procedia, Vol.18, 2012, pp. 560 - 570 . https://doi.org/10.1016/j.egypro.2012.05.068

[24] K. Mani and K. Siddappa Naidu ," Fuzzy Logic Control Based Three Phase Shunt Active Filter for Power Quality Improvement in Distributions System," ARPN Journal of Engineering and Applied Sciences, Vol. 11, No. 2, January 2016, pp.1127-1132.

[25] K. Ramash Kumar, S. Jeevananthan, "Analysis, Design and Implementation Of Hysteresis modulation sliding mode controller for negative output elementary boost converter", Journal of Electric Power Components and Systems, 40:3, 292-311, 2012. https://doi.org/10.1080/15325008.2011.631085.

[26] P. Sivakumar, V. Rajasekaran, K. Ramash Kumar, "Investigation of Intelligent Controllers for Varibale Speeed PFC Buck-Boost Rectifier Fed BLDC Motor Drive," Journal of Electrical Engineering (Romania), Vol.17, No.4, 2017, pp. 459-471.

[27] R V D Rama Rao, K. Ramash Kumar, Subhransu Sekhar Dash," Voltage regulation and harmonic suppression of transfromerless based DSTATCOM in power system, Journal of Electri- cal Engineering, Volume 10/4, December 2010, pp. 158-163, ISSN 1582-4594.

[28] V D Rama Rao, Dr.Subhransu Sekhar Dash and K. Ramash Kumar, "Simulation verification of dynamic voltage restorer using hysteresis band voltage control," Journal of Electrical Engineering: Vol. 11, 2011, Edition: 4. pp. 10-16

[29] T.Padmapriya and V.Saminadan, "Utility based Vertical Handoff Decision Model for LTE-A networks", International Journal of Computer Science and Information Security, ISSN 1947 5500, vol.14, no.11, November 2016.

[30] S.V.Manikanthan and D.Sugandhi “Interference Alignment Techniques For Mimo Multicell Based On Relay Interference Broadcast Channel "International Journal of Emerging Technology in Computer Science \& Electronics (IJETCSE) ISSN: 0976-1353 Volume- 7 ,Issue 1 -MARCH 2014.

[31] S.V.Manikanthan and V.Rama“"Optimal Performance Of Key Predistribution Protocol In Wireless Sensor Networks" International Innovative Research Journal of Engineering and Technology ,ISSN NO: 2456-1983,Vol-2,Issue -Special-March 2017.

[32] P. Sivakumar, V. Rajasekaran, K. Ramash Kumar, "Investigation of Intelligent Controllers for Varibale Speeed PFC Buck-Boos Rectifier Fed BLDC Motor Drive," Journal of Electrical Engineering (Romania), Vol.17, No.4, 2017, pp. 459-471. 